\title{
The Annual Journal Impact Factor Saga
}

\author{
Johannes Czernin
}

David Geffen School of Medicine at UCLA, Los Angeles, California

$T$ reached a new milestone at 10.057 and now ranks \#3 among all imaging journals. This achievement should not be overhyped, but it does provide evidence for the high visibility of the published work. We are aware that the calculation of the JIF has changed. Clarivate Analytics announced that it was moving toward a future that calculated the JIF based on the date of electronic publication and not the date of print publication (1). Thus, citations of early content were included in the calculation of the JIF for 2020, and drops in JIF will invariably follow in 2021. However, the overall JNM ranking improved, and $J N M$ is the \#1 publication among all nuclear medicine and molecular imaging journals (Fig. 1).

This is a tribute to the great contributions of diverse scientists from all areas of the field. Three of the top 10 articles contributing to the JIF calculation describe advances in imaging instrumentation (2-4), with the remaining 7 introducing various important aspects of theranostics (standardization of image interpretation (5), new targets and probes (6-8), translational or clinical PSMA-targeting diagnostic studies $(9,10)$, and therapeutic approaches $(11))$.

It is thus evident that theranostics and the search for novel and relevant targets remain at the forefront of nuclear medicine research. However, revolutionary advances in instrumentation will open new and exciting research opportunities. Similarly, artificial intelligence will find its way into the clinic through solidly designed clinical studies (12). The high JIF, with the associated high visibility of the journal, will continue to attract leading basic and clinical scientists from oncology, neurology, cardiology, endocrinology, infectious diseases, and other fields. Continuation of scientific growth and advances is a

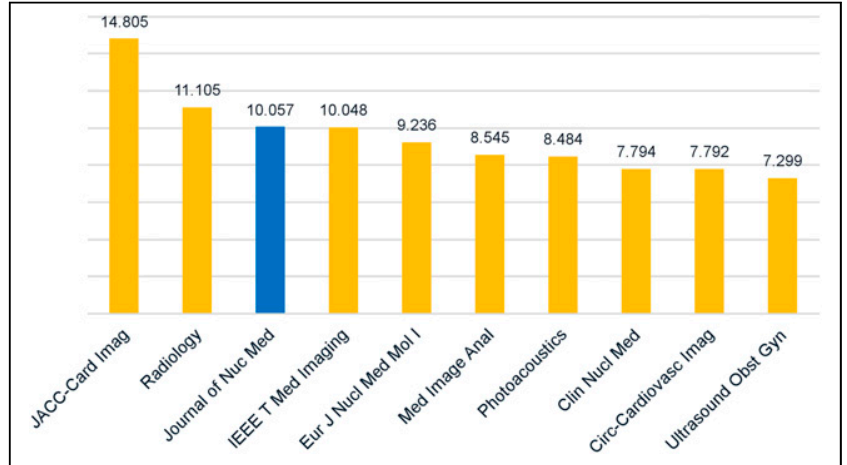

FIGURE 1. JIF: top 10 in medical imaging (June 30, 2021).

Published online July 8, 2021.

COPYRIGHT (C) 2021 by the Society of Nuclear Medicine and Molecular Imaging. DOI: 10.2967/jnumed.120.262860 condition for the sustainable success of nuclear medicine, molecular imaging, and theranostics (13). With significant industry buy-in (14), we expect further clinical translation into powerful theranostic approaches that we will publish in our flagship journal.

I am grateful for the support of SNMMI and its publications committee, the invaluable contributions of our staff, the critical input from our editorial board members, and the hard work and creativity of the team of national and international associate editors who made this success possible.

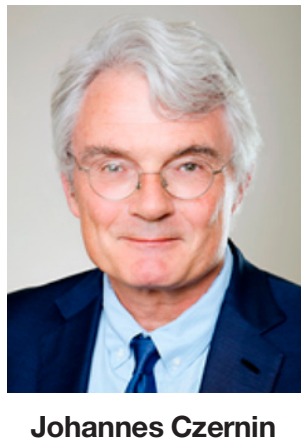

\section{REFERENCES}

1. Quaderi N. The JCR reload and a look ahead to the introduction of early access content in 2021. Clarivate website. https://clarivate.com/blog/the-jcr-reload-and-a-lookahead-to-the-introduction-of-early-access-content-in-2021/. Published October 26, 2020. Accessed July 2, 2021.

2. Cherry SR, Jones T, Karp JS, Qi J, Moses WW, Badawi RD. Total-body PET: maximizing sensitivity to create new opportunities for clinical research and patient care. $J$ Nucl Med. 2018;59:3-12.

3. Badawi RD, Shi H, Hu P, et al. First human imaging studies with the EXPLORER total-body PET scanner. J Nucl Med. 2019;60:299-303.

4. van Sluis J, de Jong J, Schaar J, et al. Performance characteristics of the digital Biograph Vision PET/CT system. J Nucl Med. 2019;60:1031-1036.

5. Eiber M, Herrmann K, Calais J, et al. Prostate Cancer Molecular Imaging Standardized Evaluation (PROMISE): proposed miTNM classification for the interpretation of PSMA-ligand PET/CT. J Nucl Med. 2018;59:469-478.

6. Kratochwil C, Flechsig P, Lindner T, et al. ${ }^{68} \mathrm{Ga}$-FAPI PET/CT: tracer uptake in 28 different kinds of cancer. J Nucl Med. 2019;60:801-805.

7. Lindner T, Loktev A, Altmann A, et al. Development of quinoline-based theranostic ligands for the targeting of fibroblast activation protein. J Nucl Med. 2018;59:1415-1422.

8. Loktev A, Lindner T, Mier W, et al. A tumor-imaging method targeting cancerassociated fibroblasts. $J$ Nucl Med. 2018;59:1423-1429.

9. Roach PJ, Francis R, Emmett L, et al. The impact of ${ }^{68}$ Ga-PSMA PET/CT on management intent in prostate cancer: results of an Australian prospective multicenter study. J Nucl Med. 2018;59:82-88.

10. Giesel FL, Knorr K, Spohn F, et al. Detection efficacy of ${ }^{18}$ F-PSMA-1007 PET/CT in 251 patients with biochemical recurrence of prostate cancer after radical prostatectomy. J Nucl Med. 2019;60:362-368.

11. Giesel FL, Kratochwil C, Lindner T, et al. ${ }^{68}$ Ga-FAPI PET/CT: biodistribution and preliminary dosimetry estimate of 2 DOTA-containing FAP-targeting agents in patients with various cancers. J Nucl Med. 2019;60:386-392.

12. Buvat I, Orlhac F. The T.R.U.E. checklist for identifying impactful artificial intelligence-based findings in nuclear medicine: is it true? Is it reproducible? Is it useful? Is it explainable? J Nucl Med. 2021;62:752-754.

13. Weber WA, Czernin J, Anderson CJ, et al. The future of nuclear medicine, molecular imaging, and theranostics. J Nucl Med. 2020;61(suppl 2):263S-272S.

14. Calais J. FAP: The next billion dollar nuclear theranostics target? J Nucl Med. 2020; 61:163-165. 